\title{
Between the Hero and the Shadow: Developmental Differences in Adolescents' Perceptions and Understanding of Mythic Themes in Film
}

\begin{abstract}
This study engages theories of film and myth in culture through an experimental study of high school and college students' perceptions of a forty-three-minute edited episode of a heroic action film. Participants were tested for their understanding of program themes as well as for their selection of role models. The authors find significant differences in younger and older adolescents' understanding of heroic themes, mythic archetypes, and other abstract program messages about the duality of human existence (i.e., we have both good and evil qualities). This study provides a developmental perspective to the semiology of myth, thereby contributing to theories of media, culture, and child development.
\end{abstract}

Keywords: media theory; child development; Jung; myth; psychology; critical cultural theory; media psychology; Batman

After the catastrophic terrorist attacks on September 11, the United States faced what seemed like a new and uncertain world. The trauma of such loss of life and of unexpected destruction left many Americans feeling victimized, looking for answers, and dealing with unimaginable bereavement. Powerful emotions are to be expected after a traumatic event, as they are part of the human process of grieving.

It is understandable, under the circumstances, that many people turned toward realms well equipped with vocabulary and scripts about good and evil, such as religion, spirituality, and law, that enable the processing of such pain. For example, President Bush called the war on terror a struggle of "good" ver-

Authors'Note: This research was supported by a grant to the Children's Digital Media Center by the National Science Foundation (Grant No. 0126014) whose support we gratefully acknowledge. We also thank the schools and participants of this study as well as Robert Ramsay, Brian Mahler, Mickey Lee, and Bonnie Strong for their assistance in coding data. Request for reprints should be directed to Sean M. Zehnder, now at Northwestern University.

Journal of Communication Inquiry 28:2 (April 2004): 122-137

DOI: $10.1177 / 0196859903261797$

(C) 2004 Sage Publications

122 
sus "evil" (Washington Post 2002b) and declared that all who are not "with us" are "with the terrorists" (Washington Post 2002a). In attempting to provide a sense of hope and shared fate, President Bush invoked mythic metaphors and rhetoric of an epic struggle.

Myth is an important source of cultural scripts that describe "right" and "wrong" ways to cope with trauma (Campbell 1988). The story of Orestes serves as a myth about the creation of a justice system and provides an example for why vengeance, or vigilante justice, cannot stand. More specifically, Aeschylus's Oresteia portrays the pursuit of vengeance by Orestes and Electra for the murder of their father. In the final scene of the Eumenides, Orestes is brought to trial by a tribunal who must determine the fates of those who choose revenge. In this scene, Athena declares that although she understands his desire for revenge, "His father's crimes / drag him before these goddesses, and there, / for all his boasting, his destruction comes-/ dread silent anger crushing him to dust" (Aeschylus Eumenides 1159-62).

In the event of a personal trauma, society often intervenes on behalf of the victim to ensure that the perpetrator(s) is properly identified and punished in a manner befitting the highest ideals of that society. In the case of September 11, however, the trauma was experienced collectively, begging the question, who is to intervene on behalf of the victim when society itself has been victimized? Although September 11 was seemingly unprecedented in modern America, human civilization has a long history of collective pain and has long produced cultural scripts about heroes who triumph over evil and serve as examples for how society itself can own its dark impulses. The line between justice and revenge can become blurred when our own civilization and codes of living are under attack.

This study begins with the observations that (1) people often look to heroes to help them overcome what seemed to be insurmountable obstacles and that (2) the majority of these heroes and stories of triumph are circulated through mass media such as television and film. This study is intended to contribute to our understanding of how these cultural scripts are perceived and processed by individuals. After all, words like good and evil, emotions such as hatred and vengeance, and many of our highest ideals for the civilized world are, in part, products of our culture: myths, heroes, legends, and rituals.

Central to the research question and methodology is an implicit theory of the way that archetypes are articulated by a culture into specific myths and rituals. Societies do not exist without communication and representation, and therefore socialization must be, in part, the learning of myths, rituals, and other archetypal articulations of a culture (Hall 1997).

Our purpose here is to use a film about one popular mythic character, Batman, as a stimulus to investigate developmental and gender differences in adolescents' understanding about the internal struggle with one's dark impulses, 
or "shadow." Both developmental and communication theories are used to frame our inquiry.

\section{Literature Review}

\section{Archetypes and the Collective Unconscious}

The theoretical framework for this study is largely drawn from the work of Jung as well as from scholars in comparative mythology, film criticism, and developmental psychology. Among Jung's $(1954,1958)$ theoretical contributions to developmental psychology, the concepts of archetypes and the collective unconscious are two of the most important. The idea of the collective unconscious builds upon the work of Freud by dividing the unconscious into a personal unconscious, containing images and impulses stored from an individual's life experiences, and a collective unconscious, containing a vast store of shared primordial, cultural images, and impulses, known as the archetypes (Jung 1958). We explore several archetypes here including the hero, the shadow, the heroine, the anima, the animus, the wise old man, the father, the mother, the son, and the villain.

The hero archetype involves the central character, or protagonist, who must temporarily separate from the ordinary world to experience a series of physical or psychological trials. More specifically, the archetypal heroic story involves the following: something taken, a journey, deeds, a return bringing something from the world abroad, and a changed hero (Campbell 1988). The hero's courage, strength, resolve, cunning, and skill to overcome dangers are tested during the journey. The hero comes to some epiphany that allows for a return to and restoration of the Ordinary World (Campbell 1968; Voytilla 1999). The quest is often personal: for example, to find love, to make peace with the past, to learn humility (Voytilla 1999).

According to Jung (1959a), the shadow archetype resides as an image within the collective unconscious that "rises up" to protect a person in a time of danger. The shadow is protective and constructive when people fight to defend themselves but also carries with it the potential for evil (Hall and Nordby 1973). In particular, the shadow turns dark and sinister when people seek revenge and retribution (Calvert et al. 2001).

For healthy, full-bodied functioning, people must integrate their shadows into their personalities (Hall and Nordby 1973). The process of integration is not easy, and there is no promise that an individual who suffers a serious trauma will ever overcome the emotions of hatred, fear, guilt, and shame associated with his or her shadow. For Jung (1959a), the resistance to reintegrate the shadow manifests itself overtly through denial and avoidance, as well as 
covertly through the repression and projection of unconscious impulses and feelings. For instance, one can project one's own evil impulses onto others so that the battle of good versus evil is only an external one, rather than the more complex inner struggle that we all face to do moral acts. Individuals, with all their faults, need to be loved so that they can go through a process of reintegration.

The anima, the female principle of males, and animus, the male principle of females, are also key archetypes in Jung's collective unconscious (Hall and Nordby 1973). In heroic tales, we believe that the anima provides the feminine principle of male characters that allows them to feel compassion and walk away from the dark side of their shadows. The anima can emerge through a relationship with a loved one that curbs the more violent tendencies of traditionally stereotyped male functioning, or at least channel those impulses into protection rather than mere destruction.

\section{Myth as Discourse}

Barthes (1957) and Hall (1993) suggest that myth is best described as a particular form of speech wherein the meanings are encoded with lower order significations, such as simple icons. Hall (1993) argues that codes are required for intelligent discourse. In the case of myth, the codes are very often naturalized and thus experienced as innocent speech (Barthes 1957). To last, myth must be distributed to different audiences via social experiences, and this circulation takes place through discourse (Hall 1993).

Treating myth as a type of naturalized speech helps explain the circulation and recirculation of mythic heroes in popular culture. That is, the meaning of myth emerges in social practice from the circulation of archetypes in media discourse.

Since myth is encoded speech, it is also important to consider the processes of perception and decoding (Hall 1993, 509). Barthes (1957) describes three different ways of reading myths. First, one can allow the concept to "fill the form of the myth without ambiguity," so that the process begins with a concept and seeks a form for it. Second, one can focus on the signifier (or the way the message is encoded), allowing for the deciphering of the myth while recognizing the distortion of the message. Third, one can view the mythic meaning and the form of its presentation as an inextricable whole, or an ambiguous signification. What is crucial to recognize in this framework is the role of perception and decoding processes in the understanding of classic myth, for as this study will demonstrate, adolescents' perceptions and understanding of classic mythic themes such as the struggle of good over evil vary by the developmental level of those who see and hear the same exact story. 


\section{The Role of Myth in Popular Culture}

Myth and religion prepare people for moments of trial by cultivating fundamental attitudes toward existence. Myth outlines the taboos of a civilization, such as "thou shalt not kill"; the punishments for violence against others, such as "an eye for an eye"; and the circumstances under which violence may be acceptable, such as self-defense or the protection of others from tyranny (Bataille 1986).

The mythic hero's journey is compelling because it dramatizes the struggles that all people must face: that of choosing the right path of justice over the dark path of revenge (Kotler and Calvert 2003). The hero's story often teaches a social lesson about how we should act and what we should aspire to when faced with adversity in our own lives. Power and nurturance are two qualities of effective models (Bandura 1997)—qualities that many heroes possess.

\section{The Myth of Batman}

Among the contemporary myths of American culture, superheroes like Batman are popular (Pecora 1992; Terrill 1993), in part due to the universality of the themes they portray: the struggle of good versus evil, between restraint and anger, between justice and revenge. Bruce Wayne's struggle and triumph to heroism is born in the traumatic murder of his parents. Because of these events, Batman, Wayne's alter ego, has the potential to be evil, to become dark and sinister if he succumbs to revenge even as he fights for justice. He finds integration when he finds acceptance by others, particularly by the woman he loves.

The story of the murder of Thomas and Martha Wayne is essential to the myth of Batman. In most accounts, Batman is born from the vow of Bruce Wayne to avenge the senseless killing of his parents. In Batman Forever, a careful account is given for each of the main heroes and villains: the murder of Bruce Wayne's parents; the murder (we witness) of Dick Grayson's family; the disfigurement of Harvey Dent by a mobster. In the case of nearly every main hero or villain, an alter ego is born of the trauma, driven by revenge and hate, to a life of either good or evil.

Few cultural texts so blatantly confound good and evil polarities as Batman Forever. In Batman Forever, violence is the modus operandi for traumatized heroes and villains, and the line between good and evil is drawn on razor-thin distinctions of degree and implied intention (e.g., for what reasons is the character employing violence?). Batman is just as violent as many of the villains, but his means are not seen as evil, because he uses aggression only when called upon to stop the violence of another. That both heroes and villains are violent lends itself to complex questions about abstract morality: What degree of jus- 
tice is acceptable for a victim to pursue against the villain? When is violence justified? Is it possible to be totally good or totally evil?

\section{Media Role Models}

Films and television programs are an important source of role models for children and young adults. Because we look up to and emulate media heroes, they can "inspire children to greatness" (Anderson and Cavallaro 2000) or, conversely, cultivate aggressive and antisocial behaviors (Bandura, Ross, and Ross 1963/2001). It is this ability for superheroes to teach antisocial, aggressive behaviors that is at the heart of the debate about curbing children's exposure to aggressive television programs (Calvert 1999). What qualities do children look for in their role models?

Gender is one important consideration. Children look for content that is "for them," and gender is one important piece of this determination (Bandura, Ross, and Ross 1963/2001; Calvert 1999). For example, girls are more likely to choose girls and women as role models, whereas boys tend to select boys and men (Anderson and Cavallaro 2000).

Personal attributes are another factor that influences role-model selection. In the Anderson and Cavallaro study (2000), most children said they chose their heroes because they are nice, helpful, and understanding. For young women, the perception of self-efficacy in a female heroic character increased the character's attractiveness as a role model, and for both young men and women, the perception of the heroic character as a nurturer was positively related to selecting him or her as a role model (Calvert et al. 2001).

\section{Comprehension of Narrative}

Children's understanding of television programs and movies depends on their age. Although comprehension of televised narratives reaches maturity around age ten (Calvert 1999; Collins 1970; Wartella 1980), the major themes of movies may require a higher level of abstraction, as they involve complicated and abstract psychological conflicts such as the tension between a character's conscience and his or her shadow. Even during adolescence, comprehension of extremely abstract moral principles, such as forgiveness over revenge and the nuances of good and evil as relative rather than absolute qualities, may still be difficult for youths to understand (Piaget 1932/1977; Kohlberg 1968/2001). Thus, we anticipated age differences in understanding concepts about the shadow, revenge, and heroism.

The nature of an individual's moral reasoning also changes as he or she ages. Piaget (1932/1977) describes developmental differences in an individ- 
ual's orientation to retributive justice, a focus of our study. Although the philosophy of an eye for an eye may have its roots in psychobiology, Piaget argues, "All progress in cooperation and mutual respect will be such as to gradually eliminate the idea of expiation from the idea of punishment and to reduce the latter to a simple act of reparation, or a simple measure of reciprocity" (p. 191). Thus, an eye for an eye gives way to a new philosophy of justice based on a type of elementary social contract: do unto others as you would have them do unto you.

The research of both Piaget (1932/1977) and Kohlberg (1968/2001) suggests that there are important developmental differences in individuals' moral reasoning. Therefore, it is likely that younger subjects will perceive the themes or morality in Batman Forever differently than older subjects, especially the themes of revenge and justice.

While no studies relate age to understanding of archetypes, we expected older participants to be more likely to recognize and understand the archetypes because they have had more exposure to these images throughout their lives. Archetypes, after all, are the "elementary ideas" (Campbell 1988) that a person learns and continually re-experiences over the course of a lifetime.

\section{The Present Study}

The purpose of this study was to compare younger and older adolescents' understanding of a filmed narrative, Batman Forever, which develops heroic themes in a context where the main characters struggle with their desires for vengeance after major personal losses. The main hypothesis was that older participants would understand the complex elements of the plot more so than would younger participants, and therefore, the older participants would be less vulnerable to the adverse effects of violence exposure. We also predicted that participants would identify most with same-gendered role models, particularly with the heroic attributes of those characters.

\section{Method}

\section{Participants}

Participants were 107 high school students (mean age 15.6 years) and 68 college students (mean age 20.5 years) who lived in a small city and a metropolitan area. There were 102 females and 81 males.

\section{Procedure}

The 47.48-minute stimulus program had been edited from a 122-minute film to include only those scenes and characters considered central to three 
main plots: (1) Bruce Wayne falls in love with Chase Meridian, and through her love and acceptance of both sides of his identity, he is able to accept and integrate the duality of his nature; (2) Robin (Batman's sidekick) transcends his desire for revenge by saving the life of the villain Two Face and thus begins a process of healing; and (3) Batman and Robin become partners in fighting crime, becoming the fabled dynamic duo known throughout the past several decades through comic books and television shows.

Participants viewed the edited film and then answered forty-seven questions measuring comprehension and perception of the program content, themes, characters, and archetypes. The questionnaire was designed to measure (1) comprehension of the program content, (2) understanding of the hero and shadow archetype, (3) perception of the major program themes, and (4) perception of the major characters in the program. Following procedures developed by Collins (1970), thirty-seven adults rated questions as either central or incidental to the content of the program. Central items were defined as those that were essential to understanding the plot. Incidental items were those that were irrelevant to the plot. Items were retained that had a 70 percent minimum centrality rating.

For five successive class periods during the day, two classes of high school students watched the video and answered the questionnaire in the school auditorium. The video was projected onto a large, white screen on the stage in the auditorium, and the sound was played from two 9-inch speakers and a subwoofer from the center of the auditorium. Subjects were also instructed not to discuss their answers until everyone had completed the survey.

Of the sixty-eight college students, twenty attended one of four in-classroom viewings identical to that of the high school procedure. The remaining college students completed both the viewing and the survey over the Internet at a centralized Web site.

In a comparison between twenty college students who watched the video in a classroom setting and filled out paper questionnaires and twenty college students who completed an online presentation and questionnaire, there were no significant differences in any of the targeted outcome measures. Therefore, the classroom and online procedures were comparable.

\section{Results}

\section{Comprehension of the Central Program Content ${ }^{1}$}

Twelve free-recall items measured each student's comprehension of the major plots and themes of the program. These textual responses were first scored by a single coder on a scale of 1 to 3 , where $1=$ does not comprehend, $2=$ partially comprehends, and $3=$ totally comprehends. 
A sample item is "Why did Bruce Wayne become Batman?" Full comprehension credit was given for responses such as "to make sure what happened to him never happened again." Partial comprehension credit was given for the response "for revenge." No credit was given for the response "b/c he was already Batman."

A composite score of comprehension was calculated by summing responses to shadow comprehension questions and supported our first hypothesis that college students would understand program content better than high school students, ${ }^{2}$ particularly material related to the shadow. Previous viewing was also associated with better comprehension of program content. ${ }^{3}$ No gender differences were apparent in comprehension.

\section{Perceptions of Characters ${ }^{4}$}

Four questions measured the perception of the major characters as role models by asking the respondent the degree to which they "want to be like" Batman, Robin, Chase, and Two Face, respectively, on a 4-point Likert scale where $1=$ not at all, $2=$ a little bit, $3=$ somewhat, and $4=a$ whole lot .

We computed zero-order Pearson correlations to examine the qualities of heroes that made them appealing as role models to high school and college students. The qualities that made Batman and Robin most appealing as role models to students were perceptions that the characters were compassionate (Batman, $r=.24$; Robin, $r=.23$ ) and that they had a conscience (Batman, $r=.26$; Robin, $r=.14)$. Not surprisingly, girls were more likely to identify with Chase Meridian, the female heroine $(r=.26)$, and males were more likely to identify with Batman, the male hero $(r=-.14)$. The high school more so than the college students were likely to identify with Two Face, the villain $(r=-.16)$; interestingly, those who did not understand the program well were also more likely to identify with the villain $(r=-.19)$.

Most participants, regardless of age and gender, thought that Batman and Robin were guided by their consciences in their actions. For Batman, the mean level of perceived conscience was $3.36(S D=.76)$, and for Robin, the mean was $3.61(S D=.66)$. On a scale of 1 to 4 , the scores fell between somewhat and a whole lot.

\section{Revenge}

A measure for revenge was created by combining the scores for the responses from two questions that asked how much the participant agrees with the following statements: "If someone is evil, then they deserve to die" and "It is ok for Robin to get even for what happened to his family." Responses were 
rated on a scale from 1 to 3 , where $1=$ questions whether anyone can ever be judged to be totally evil (e.g., "I do not believe that people are all good or all evil" or "Who are we to judge?"), 2 = suggests there are slight shades of gray in evil and therefore death is not a proper punishment (e.g., "There are reasons they are evil, and maybe they can change"), and $3=$ suggests that people are either good or evil and there are no shades of gray (e.g., "They deserve to die because they are evil").

The question about the justification for Robin's "getting even" for the murder of his family was scored for the degree to which the participant's response advocates getting even (i.e., an eye for an eye), where the response $1=$ does not believe in an eye for an eye and believes revenge to be wrong (e.g., "because justice will be served on it own"), 2 = does not rule out getting even but would prefer the punishment be humane (e.g., "yes, but only to help others"), and $3=$ supports the right of Robin to get even (e.g., "an eye for an eye").

The composite score was intended to measure the willingness of the participants to seek revenge, where their willingness to judge others as evil and their degree of belief in an eye for an eye served as a measure of such a sentiment. This litmus is consistent with the theoretical framework of Piaget (1932/1977). The higher the score for revenge, the more likely the respondent was to believe the world to be black and white in terms of both the moral virtue of others (good or evil) and the appropriate punishment of wrongdoers.

With development, we expected more understanding of the concept that people are not good or evil but a mixture of the two. Such an understanding should be associated with a decrease in a desire for revenge. As predicted, college students were less likely to be vengeful than were high school students, ${ }^{6}$ and females were also less likely to be vengeful than were males. ${ }^{7}$

\section{Knowledge of Archetypes}

Finally, participants were asked to identify which character best embodied the following archetypes: wise old man, father figure, son figure, villain, hero, heroine, and mother figure.

Consistent with our hypothesis, a greater proportion of older rather than younger students identified the archetypes portrayed in the program. Even so, selections were generally consistent for all archetypal roles, although they varied somewhat depending on the age of the participants in relation to the age of the characters.

Not surprisingly, 94.4 percent of the high school participants and 92.4 percent of the college students selected Batman as the hero, with Robin (high school $=1.9$ percent; college $=3.8$ percent $)$ and Alfred the butler (high school $=$ 0.9 percent; college $=3.8$ percent) as infrequent selections. Two Face was con- 
sidered the villain by 94.4 percent of high school students compared with 97.5 percent of college students.

For the father figure, 64.8 percent of the younger subjects chose Batman, and 27.8 percent chose Alfred, while the figures for the college students were slightly higher for Batman (73.4 percent) and about the same for Alfred (26.6 percent). Both groups saw Robin/Dick Grayson as the son figure (high school $=87.0$ percent ; college $=87.3$ percent $)$, with Batman as the second most frequent response (high school $=12.0$ percent; college $=8.0$ percent). Alfred was perceived as the wise old man by 83.3 percent of the high school students versus nearly 100 percent of the college students.

The main difference between the high school and the undergraduate samples involve the archetypes of heroine and mother figure. Of the high school students, 60.2 percent perceived Chase Meridian as the heroine compared with 86.1 percent of the college students. The majority of high school students (86.1 percent) viewed Chase Meridian as the mother figure, in contrast to only 67.1 percent of college students. Interestingly, the second most frequent response by the college students was Alfred (27.8 percent), with far fewer high school students (5.6 percent) making this choice. The latter findings suggest that with age, the biological sex of the character was less relevant for judgments of mother than was the kind of role played.

\section{Discussion}

The purpose of this study was to examine the processes of reception and decoding of mythic depictions in film. Our findings demonstrate heterogeneous reception of a mythic depiction across at least one important dimension, age, even when the individuals under observation share a common language, culture, and history. After all, we had anticipated that a popular contemporary myth about Batman would be uniformly understood, especially by the time a child reached adolescence, since the archetypes of hero, villain, heroine, good, and evil and the theme of the human struggle against the desire for revenge are commonplace in popular culture.

Development clearly influenced the interpretation of the mythic structure put forth in the story narrative. For example, college students better understood complex concepts about the duality of human nature, that is, that we can be both good and evil, than did high school students. Past research about comprehension of television narratives documents an age shift about age ten in children's ability to understand abstract themes and character motivations (Calvert 1999; Collins 1970; Wartella 1980). The present research adds to this body of research by demonstrating that comprehension of complex concepts presented in film continues to develop over time and is not totally complete during middle adolescence. 
The age changes we found in understanding the price of revenge and the importance of rising above retribution may well reflect developmental changes associated with moral development (Kohlberg 1968/2001; Piaget 1932/1977). Specifically, simple explanations of good and evil and the validity of revenge as a strategy for loss reflect an absolute rather than a relative view of morality. Only with age did participants come to understand that human nature is not nearly so simple. We all have the capacity for destructive acts; we all have the capacity for mercy. The development of these understandings is probably a general cognitive skill that is then brought to bear on experiences, including adolescents' interpretations of filmed narratives.

A central policy issue in the media violence area is the concern that viewers emulate superheroes and become aggressive themselves. There is little evidence to support that concern here. We found that participants identified with Batman primarily when they perceived him to be compassionate and to have a conscience-findings that have previously been documented for compassion and identification with a female hero (see Calvert et al. 2001). By looking at differences in reception of a violent media depiction, this study comes closer to what Hall (1993) describes as the appropriate epistemological stance toward the question of media violence, since "representations of violence on the television screen 'are not violence but messages about violence", (emphasis added, pp. 510-11). These findings suggest that for superheroes, positive moral qualities are far more important for role model status than are negative, aggressive ones.

However, there is one important caveat to this interpretation. That caveat is the younger participants' greater tendency to identify with the villain. Those who identified with the villain did not understand the program plot well. Hence, poor comprehension by young viewers may be a key reason why they act aggressively after exposure to violent media portrayals (e.g., Liss, Reinhardt, and Fredriksen 1983). The findings suggest that comprehension mediates perceptions of violent characters and that younger viewers are most at risk for detrimental effects after exposure to media violence as they are less competent at disentangling aggressive action from the prosocial resolution.

That individuals understand mythic messages differently across developmental dimensions, also calls into question the foundation of Debord's (1967/1994) argument that contemporary society is moving away from the tradition where the circulation of myth "ensures community" (pp. 132-33). In fact, our findings suggest that even in a "real historical community," mythic messages are always polysemous; audiences are heterogeneous even when they share a common language and a common history.

However, our intention is not to downplay the prevalence or importance of mythic invocations by those in the media spotlight, such as our political leaders. After all, "Bourgeois ideology continuously transforms the products of 
history into essential types" (Barthes 1957, 155), as these essential types have the power to displace some of the anxiety generated by all the contingencies associated with human civilization. "Myth does not deny things," Barthes (1957) writes. "On the contrary, its function is to talk about them; simply, it purifies them, it makes them innocent, it gives them a natural and eternal justification, it gives them a clarity which is not that of an explanation but that of a statement of fact" (p. 143). This, in part, explains the use of mythic rhetoric by President Bush in the wake of the September 11 terrorist attacks. For example, President Bush labeled nations that are suspected of harboring terrorists as an "axis of evil" (Office of the Press Secretary 2002).

How we come to understand complex concepts like good and evil, of how to be a hero rather than a sinister villain, are at the heart of how a civilization and a people remain moral and just, even in the face of the darkest of times. We believe that media play an important role here. Myth draws on the history of a culture, as well as the vast reservoir of archetypes, to naturalize values through discourse. In contemporary culture, film is an important landscape wherein archetypal images circulate in a discourse that both reflects and is constituted by the history and prevailing contingencies of a society. According to Barthes (1957), the reduction of human experience to essences, from this perspective, is not by itself problematic. However, the use of rhetoric to transport mythic concepts such as good and evil to other political decisions, such as preemptive military strikes, can be problematic. Fear and the dark side of the shadow can be invoked through the rhetoric of good and evil, leading to additional death and destruction through war. As Barthes argues that rhetoric used this fashion is, in fact, serving a purpose other than as myth, since the motivation actually becomes a higher order signification or connotation.

In conclusion, comprehension of complex themes about good and evil play out repeatedly in our media. These stories, based in myth, give us templates for dealing with tragic events, such as the destruction of the World Trade Center and the Pentagon. The focus on justice, not revenge, is the path of heroes, and adolescents come to better understand this concept with development. We choose our heroes for compassion and moral stances not for destructive qualities. Transcending revenge is part of the human struggle, and the superheroes' quest to save others is one path that can lead to a successful resolution of this inner conflict.

Although viewers understand the myths of hero and shadow reasonably well by middle adolescence, the complexities of those messages are still not fully understood. The implication is that the message to view some people as evil will resonate most with those who reason at a less abstract level. That people of different age consume media messages on good and evil somewhat differently is more than likely true whether the themes are presented as fiction or as lead stories in the nightly news. 


\section{Notes}

1. To compute interobserver reliability, a second coder scored a random selection of forty-seven questionnaires, slightly more than 20 percent of the total responses. Interobserver reliability, calculated as two times the number of agreements divided by the total number of scores for coder 1 and coder 2, was 92 percent for comprehension scores.

2 . Due to differences in prior exposure to the program, a 2 (grade) $\times 2$ (gender) betweensubjects analysis of covariance was computed with comprehension scores as the dependent variable and prior exposure as the covariate. The two-factor ANCOVA computed on comprehension scores yielded a main effect of grade, $F(1,182)=35.476, p<.001$, and the covariate of prior exposure was also marginally significant, $F(1,182)=3.322, p=.07$. College students understood program content better than did high school students $(M=19.814$ vs. 16.964 , respectively).

3. There was a trend for college-age students to have seen the movie more often than high school students, $\chi_{(1)}^{2}=2.876, p=.09$. Seventy-four percent of college students and 63 percent of high school students reported seeing the movie before. There were no gender differences in prior exposure to the movie.

4. We conducted a 2 (grade) $\times 2$ (gender) between-subjects ANOVA with identification with characters as the dependent variable. There was a trend for males to identify with Batman, $F(1,183)=2.185, p=.095(M=2.125, S D=.108$ vs. $M=1.878, S D=.100$, respectively $)$. Females and older participants were more likely to identify with Chase Meridian than were males, $F(1,183)=15.102, p<.001(M=2.214, S D=.098$ for females vs. $M=1.657, S D=.105$ for males), and younger participants, $F(1,183)=8.667, p=.004(M=2.147, S D=.109$ for college students vs. $M=1.724, S D=.093$ for high school students). High school students were more likely to identify with the villain Two Face than were college students, $F(1,183)=4.775$, $p=.030(M=1.178, S D=.046$ for high school students vs. $M=1.024, S D=.054$ for college students). Age and gender were unrelated to students' identification with Robin.

5 . To examine this hypothesis, a 2 (grade) $\times 2$ (gender) between-subjects analysis of variance was computed with revenge scores as the dependent variable. The two-factor ANOVA computed on revenge scores yielded a main effect of grade, $F(1,152)=10.179, p=.001$, and gender, $F(1,152)=3.993, p=.047$.

6. $M=2.752, S D=.165$ vs. $M=3.444, S D=.141$, respectively.

7. $M=2.881, S D=.155$ vs. $M=3.315, S D=.152$, respectively.

\section{References}

Aeschylus, Eumenides. Ian Johnston, trans. http://www.mala.bc.ca/ johnstoi/aeschylus/ aeschylus_eumenides.htm.

Anderson, K., and D. Cavallaro. 2000. From parents to pop stars: Role models and heroes in the third millennium. http://www.mediascope.org/pubs/superher.pdf.

Bandura, A. 1997. Self-efficacy: The exercise of control. New York: Freeman.

Bandura, A., D. Ross, and S. Ross. 1963/2001. Imitation of film-mediated aggressive models. In Notable selections in human development, edited by Rhett Diessner and Jacquelyne Tiegs, 2nd ed. Guilford, CT: McGraw-Hill.

Barthes, Roland. 1957. Mythologies. Translated by Annette Lavers. New York: Hill and Wang.

Bataille, G. 1986. Erotism. San Francisco: City Lights Books.

Calvert, S. 1999. Children's journeys through the information age. Boston: McGraw-Hill.

Calvert, S., T. Kondla, K. Ertel, and D. Meisel. 2001. Young adults' perceptions and memories of a televised woman hero. Sex Roles 45 (1/2): 31-52. 
Campbell, J. 1968. The hero with a thousandfaces. Princeton, NJ: Princeton University Press. - 1988. The power of myth. With Bill Moyers. New York: Anchor.

Collins, W. A. 1970. Learning of media content: A developmental study. Child Development 41:1133-42.

Debord, Guy. 1967/1994. Society of the spectacle. Translated by Donald Nicholson-Smith. New York: Zone Books.

Hall, Stuart. 1997. Introduction. In Representation: Cultural representations and signifying practices, edited by Stuart Hall. London: Sage.

—. 1993. Encoding, decoding. In The cultural studies reader, edited by Simon During. London: Routledge.

Hall, C. S., and V. Nordby. 1973. A primer of Jungian psychology. New York: Mentor Books.

Jung, C. 1954. The archetypes and the collective unconscious. In vol. 9i of Collected Works, translated by R. F. C. Hull. New York: Pantheon Books.

- 1958. Psychology and religion. In vol. 11 of Collected works, translated by R. F. C. Hull. New York: Pantheon Books.

- 1959a. Aion: Researches into the phenomenology of the self. Translated by R. F. C. Hull, 2nd ed., vol. 9, part II. Princeton, NJ: Princeton University Press.

1959b. The basic writings of C. G. Jung. New York: The Modern Library.

Kohlberg, L. 1968/2001. The child as moral philosopher. In Notable selections in human development, edited by Rhett Diessner and Jacquelyne Tiegs, 2nd ed. Guilford, CT: McGraw-Hill.

Kotler, J. A., and S. L. Calvert. 2003. Children's and adolescents' exposure to different kinds of media violence: Recurring choices and recurring themes. In Media violence and children, edited by D. Gentile. Westport, CT: Praeger.

Liss, M., L. Reinhardt, and S. Fredriksen. 1983. TV heroes: The impact of rhetoric and deed. Journal of Applied Developmental Psychology 4:175-87.

Office of the Press Secretary. 2002. State of the union address, January 29.

Pecora, Norma. 1992. Superman/superboys/supermen: The comic book hero as socializing agent. In vol. 1 of Men, masculinity, and the media, edited by S. Craig. Newbury Park, CA: Sage.

Piaget, J. 1932/1977. Moral judgment: Children invent the social contract. In The essential Piaget, edited by H. E. Gruber and J. J. Voneche, 159-93. New York: Basic Books.

Terrill, R. E. 1993. Put on a happy face: Batman as a schizophrenic savior. Quarterly Journal of Speech 79:319-35.

Voytilla, S. 1999. Myth and the movies: Discovering the mythic structure of 50 unforgettable films. Studio City, CA: Michael Wiese Productions.

Wartella, E. 1980. Children and television: The development of the child's understanding of the medium. In vol. 1 of Mass-communication review yearbook, edited by Cleveland Wilhoit and Harold DeBock. Beverly Hills, CA: Sage.

Washington Post. 2002a. Bush doctrine begins to blur, April 3.

2002b. Bush's unease with ambiguity, April 9.

Sean M. Zehnder is a Ph.D. student at Northwestern University in the media, technology, and society program and a graduate research assistant in the Children's Digital Media Center's Digital-Kids Lab in the School of Communication. He specializes in multidisciplinary research in the field of technology and social behavior with special emphasis on immersive interactive environments and child development. His doctoral dissertation explores theories of media use through a case study of the evolution of perceptual techniques in video games 
and a series of experimental studies on the perception and cognition of 3-D interactive narratives.

Sandra L. Calvert, the director of the Children's Digital Media Center, is a professor of psychology at Georgetown University. She is author of Children's Journeys Through the Information Age (McGraw-Hill, 1999) and coeditor of Children in the Digital Age: Influences of Electronic Media on Development (Praeger, 2002). Her research examines the role that interactivity and identity play in children's learning from entertainment media through studies conducted by the Children's Digital Media Center, which is funded by the National Science Foundation. She is also involved in media policy, recently completing research about children's learning from educational and informational television programs required by the Children's Television Act. She is a fellow of the American Psychological Association. She has consulted for Nickelodeon Online, Sesame Workplace, Blue's Clues, and Sega of America to influence the development of children's television programs, Internet software, and video games. 